\title{
$24 \mathrm{GHz}$ 대역 $\mathrm{CW}$ 레이더 송수신기 설계
}

\author{
남병창 ${ }^{1}$, 채규수 $2^{*}$ \\ ${ }^{1}$ (주)유텔, ${ }^{2}$ 백석대학교 정보통신학부/RDRC KAIST
}

\section{Design of a K-band CW Radar Transceiver}

\author{
Byung-Chang Nam $^{1}$ and Gyoo-Soo Chae ${ }^{2^{*}}$ \\ ${ }^{1}$ U-Tel Co., Ltd. \\ ${ }^{2}$ Division of Information Communication Eng., Baekseok University
}

\begin{abstract}
요 약 본 논문은 절전형 센서에 사용되는 $24 \mathrm{GHz}$ 대역의 $\mathrm{CW}$ 레이더 송수신기의 설계에 관한 것이다. $\mathrm{K}$-대역의 송 수신기 회로의 기본 구조와 전력분배기와 송수신 안테나가 디자인 되었고 발진기, 주파수혼합기, 고주파 증폭기는 상 용 제품을 사용하였다. 제작된 분배기와 안테나의 성능이 측정되었고 송신 주파수와 출력전력레벨이 상용 제품에 적 용될 수 있을 정도로 양호하였다. 제안된 송수신기의 크기는 $35 \times 35 \times 10(\mathrm{~mm})$ 이며 여러 가지 제품에 사용될 수 있도록 설계되었다.
\end{abstract}

\begin{abstract}
This paper describes a $\mathrm{K}$-band $\mathrm{CW}$ radar transceiver suitable for power saving motion sensor. The presented transceiver module is designed and contains patch antennas, dielectric resonator oscillator (DRO), IF amplifier, mixer, divider. The designed divider and antenna are measured and the transmitting frequency and the power were fairly good for using in commercial applications. The transceiver is manufactured with a dimension of $35 \times 35 \times 10(\mathrm{~mm})$ and can be adapted in various applications.
\end{abstract}

Key Words : CW Radar, Transceiver, Radar sensor, Detection range.

\section{1. 서론}

일반적으로 마이크로파 레이더 센서는 수동형과 능동 형으로 구분된다. 수동형 센서는 단순히 전파를 수신하여 상황을 판단 할 수 있는 정보를 얻는다. 반면에 능동형 레이더 센서는 송신 안테나를 통해 방사되는 전파가 목 표물에 부딪혀서 되돌아오는 전파를 수신 안테나를 통해 수신할 때 생기는 도플러 천이(shift) 현상을 이용하는 것 이다[1]. 최근에는 밀리미터파 $(30-300 \mathrm{GHz})$ 대역의 레이 더 센서가 다양한 응용 분야에서 사용되고 있다. 밀리미 터파를 이용한 레이더 센서에 대한 연구가 활발히 진행 중이다[2-5]. 특히, 차량전방감지용 밀리미터파 레이더는 능동형 레이더 센서로서 차간 거리가 급격히 가까워질 경우 브레이크를 작동시켜 충돌을 경감시키거나 경보 등 을 울려 위험을 알리는 등 여러 가지 종류의 충돌 경감 및 방지 시스템에서부터 나아가 자동주행 등을 가능하게
하는 응용에 활용되는 핵심 기술이다. 또한, 자동차의 에 어백 센서로도 활용되고 있다[3-5]. 그리고 최근 에너지 절약에 대한 관심이 증폭되면서 실내 전등의 점멸을 제 어하는 절전형 센서로 널리 이용되고 있다. 현재까지는 $\mathrm{X}$ 대역 $(10 \mathrm{GHz})$ 에서 동작하는 레이더 센서가 주로 개발 되어 사용되고 있지만 센서 크기의 소형화와 새로운 기 능을 고려하여 K-밴드 대역의 레이더 센서에 대한 연구 도 활발히 진행되고 있다[6]. 절전형 센서나 자동문 감지 센서의 경우 적외선 감지 방식을 많이 사용하고 있으나 적외선의 오작동 문제와 장애물에 가려서 동작이 되지 않는 등의 문제가 있었다. 그러나 본 논문에서 제안하는 $\mathrm{K}$ 대역의 마이크로파 센서는 기존 $10 \mathrm{GHz}$ 대 제품에 비해 멀리 있는 인체 및 사물의 움직임도 보다 더 안정적이고 정밀하면서도 오차가 거의 없게 감지할 수 있는 고주파 센서이다.

반도체 제조기술의 발전으로 안테나를 제외한 회로들

*교신저자 : 채규수(gschae@bu.ac.kr)

접수일 09년 05월 11일수정일 09년 06월 20일 게재확정일 09년 7월 22일 
을 RFIC 형태로 제작하여 센서의 크기를 획기적으로 줄 이기 위한 연구도 활발히 진행되고 있다. 그러나 최근까 지도 $\mathrm{MMIC}$ 기술이 일부 사용된 제품들이 주로 사용되고 있다. 본 논문에서도 응용 제품에서 요구되는 최소한의 조건을 만족하는 제품을 개발 하기위해 발진기, 주파수혼 합기, 고주파 증폭기는 $\mathrm{MMIC}$ 형태의 상용 제품을 사용 하였고 전력분배기는 마이크로스트립(micro-stripe)라인 을 이용한 윌킨슨분배기형태로 직접 설계하였다.

레이더 센서는 신호의 변조 방식에 따라 펄스형(Pulse type)과 연속파형(CW: continuous wave)으로 나누어진다 [1]. 펄스형은 짧은 펄스를 발생 시켜 목표물에서 반사되 는 신호를 수시하여 시간에 따른 전파의 지연시간을 이 용하는 일종의 진폭변조 방식이며 목표물의 움직임과 위 치 정보를 얻을수 있다. 목표물이 다가오거나 멀어지는 경우에 수신되는 신호의 주파수가 송신 주파수와 약간의 차이가 나는데 이것을 도플러 주파수라고 한다. 연속파 $(\mathrm{CW})$ 형은 송신 안테나를 통해 특정 주파수의 전파를 계 속 보내고 목표물에 부딪혀 돌아오는 신호가 송신 주파 수와의 차이를 측정 하여 물체의 움직임을 감지하게 된 다. 특별히 주파수 변조를 이용하는 경우를 $\mathrm{FMCW}$ (frequency modulation continuous wave)라고 하며 대부분 의 센서들이 이 방식을 이용한다. 본 논문에서는 연속파 방식의 레이더를 설계 할 것이다. 레이더의 특성상 탐지 거리가 중요 한데 먼 거리의 물체를 탐지 하는 경우에는 펄스형을 사용하며 가까운 거리의 물체를 탐지 하는 경 우는 $\mathrm{CW}$ 나 $\mathrm{FMCW}$ 방식을 사용한다.

\section{2. $\mathrm{CW}$ 방식의 레이더 센서 설계}

본 연구에서 설계된 $\mathrm{CW}$ 방식의 레이더 센서의 구성도 가 그림 1에 나타나 있다. 발진기(Oscillator)에서 $24 \mathrm{GHz}$ 의 신호가 발생되고 구동증폭기(Drive amplifier)에서 증 폭이 되어 전력분배기(Power divider)를 통해 송신 안테 나로 전파가 방사 하게 된다. 목표물에 부딪혀서 주파수 천이가 생긴 전파 $(24.12 \mathrm{GHz} \pm a)$ 가 수신 안테나를 통해 들 어오면 송신 주파수 $(24.12 \mathrm{GHz})$ 와 주파수혼합기에서 두 주파수의 차이에 해당하는 주파수 신호가 IF단을 통해 신호 처리부로 전달된다. 이때 수신 신호가 매우 약하기 때문에 IF단에서 나온 신호는 1차적으로 증폭기를 통해 증폭 시킨 다음 신호처리부로 전달된다. 레이더센서의 목 표 규격이 표 1에 나타나 있다. 송신 안테나를 통해 방사 되는 출력전력레벨이 $7 \mathrm{dBm}$ 이상을 유지하게 하고 센서 의 전력 소모량을 줄이기 위해 $150 \mathrm{~mA}$ 이하의 전류를 사 용하도록 설계되었다.
[표 1] 레이더 센서의 사양

\begin{tabular}{|c|c|c|}
\hline 항 목 & 단 위 & 규 격 \\
\hline 인가전압 & $\mathrm{V}$ & +5 \\
\hline 전류 소모량 & $\mathrm{mA}$ & 150 \\
\hline 출력주파수 & $\mathrm{GHz}$ & 24.125 \\
\hline 출력전력레벨 & $\mathrm{dBm}$ & +7.0 이상 \\
\hline 크기 & $\mathrm{mm}^{3}$ & $35 \times 35 \times 10$ \\
\hline
\end{tabular}

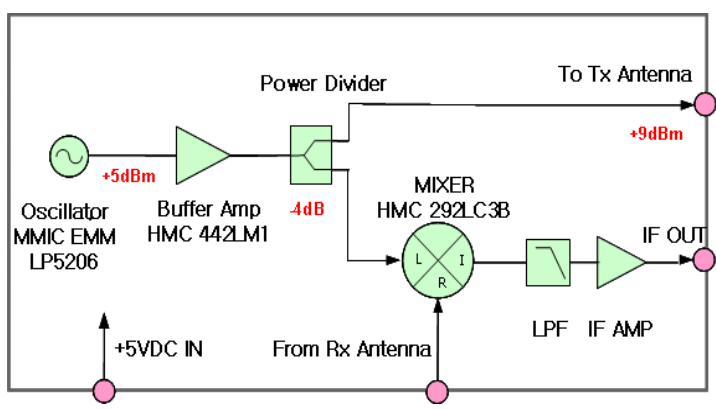

[그림 1] CW 레이더 송수신기의 구성도

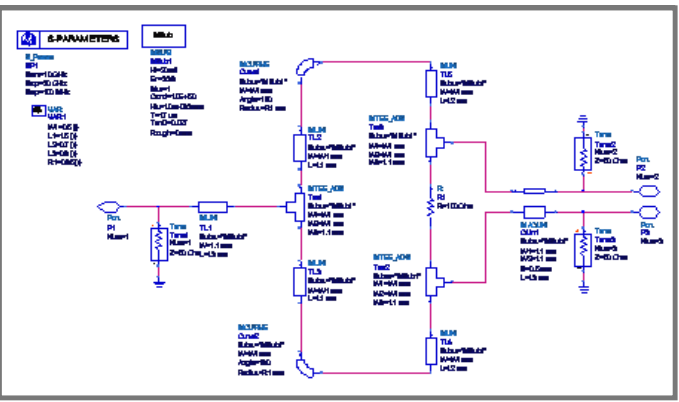

[그림 2] 전력분배기 설계도

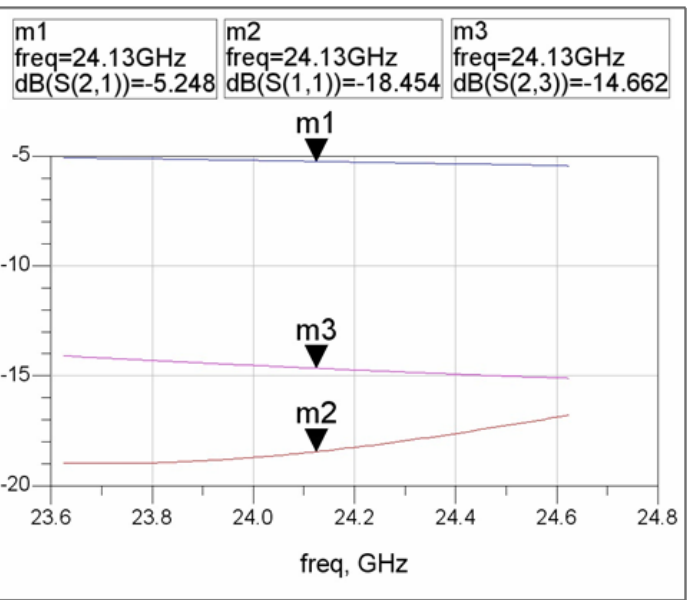

[그림 3] 전력분배기의 설계결과 
전력분배기는 그림 2와 같이 $\mathrm{ADS}$ 를 이용하여 직접 설 계되었으며 설계결과는 그림 3에 나타나있다. 전력분배 기의 기본 구조는 윌킨슨 전력 분배기이며 S-파라미터에 대한 설계결과가 양호 하게 나왔다. 실제 제작 후에 분배 기 단일 부품에 대한 측정은 하지 않았으며 송신기 출력 단의 출력레벨을 측정하는 것으로 대체하였다.

그림 4에서는 제작된 $\mathrm{CW}$ 방식의 레이더 송수신기가 나타나있다. 발진기(EMM5206 LP), 구동증폭기 (AMMC5620), 주파수혼합기(HMC292LM3C)는 상용 제 품을 사용하였으며 자세한 제품의 특성은 각 제품의 사 양에 나타나있다[7-9]. 그리고 송수신용 패치 안테나를 CST MWS를 사용한 시뮬레이션 결과를 이용하여 제작 되었다. 일반적으로 절전형 센서용 송수신 안테나는 하나 의 패치 안테나만 사용하지만 감지거리를 늘이기 위하여 두 개의 패치 어레이안테나를 사용하였다. 그림 5 에서는 완성된 송수신부와 송수신 안테나부가 조립된 상태를 보 여주고 있다.

제작된 안테나의 S 파라미터의 측정결과가 그림 6 에 나타나 있다. K-밴드 대역에서 $1 \mathrm{GHz}(\mathrm{VAWR} \leq 2)$ 이상의 충분한 대역폭을 얻었다. 그림 7에서는 송신 안테나에서 의 출력전력 파형을 보여주고 있다. 표 1 에 나타난 레이 더 센서의 출력전력레벨은 사양 ( $+7 \mathrm{dBm} @ 24.12 \mathrm{GHz})$ 보 다 높은 $+8.07 \mathrm{dBm}$ 을 얻었다. 그리고 센서의 전류소모량 을 측정 한 결과 $100 \mathrm{~mA}$ 정도로 양호한 결과를 얻었다. 전류소모량은 레이더 센서가 절전용 센서에 응용될 예정 이기 때문에 상당히 중요한 요소로 향후에도 지속적인 개선 노력이 필요한 부분으로 사료된다.

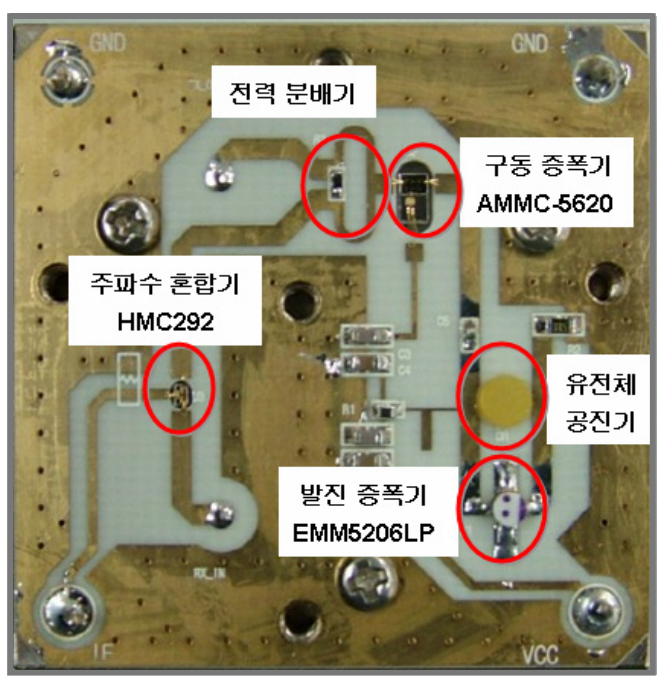

(a)

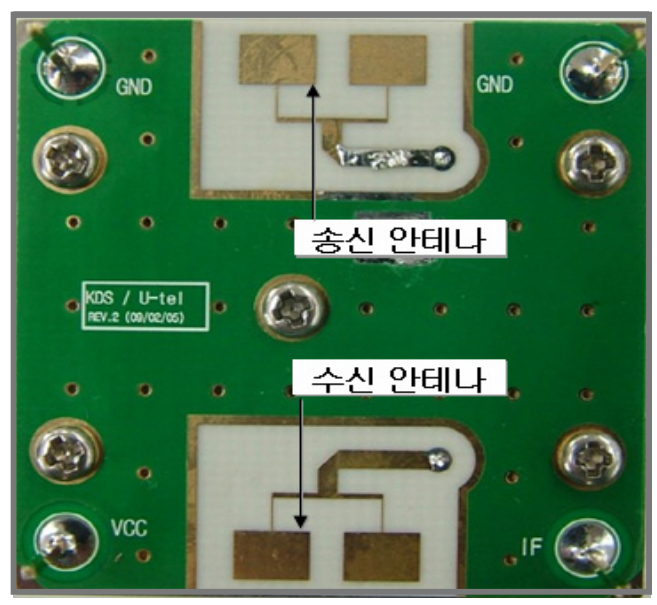

(b)

[그림 4] 레이더 송수신회로(a)와 송수신 안테나(b)

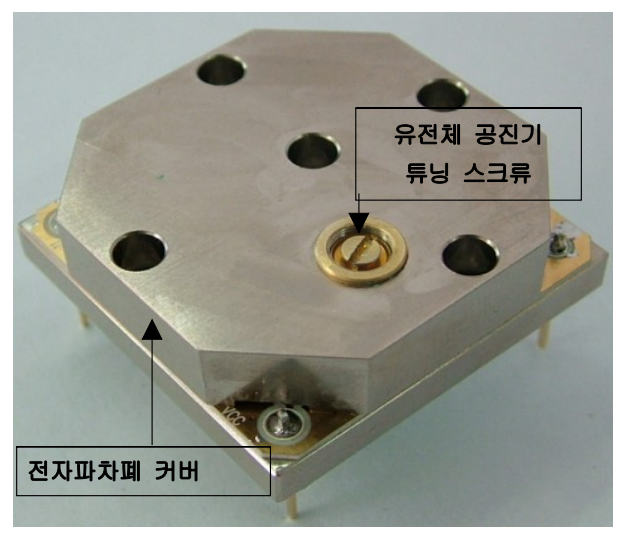

[그림 5] 완성된 $\mathrm{CW}$ 레이더 송수신기 모양

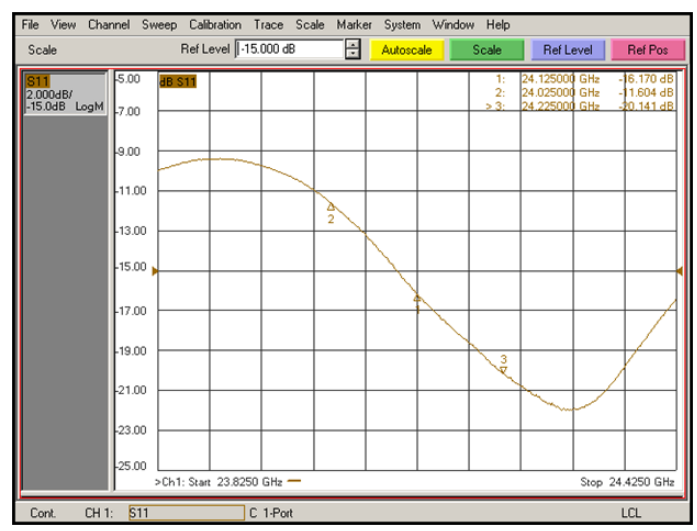

[그림 6] 측정된 안테나 S11 특성 


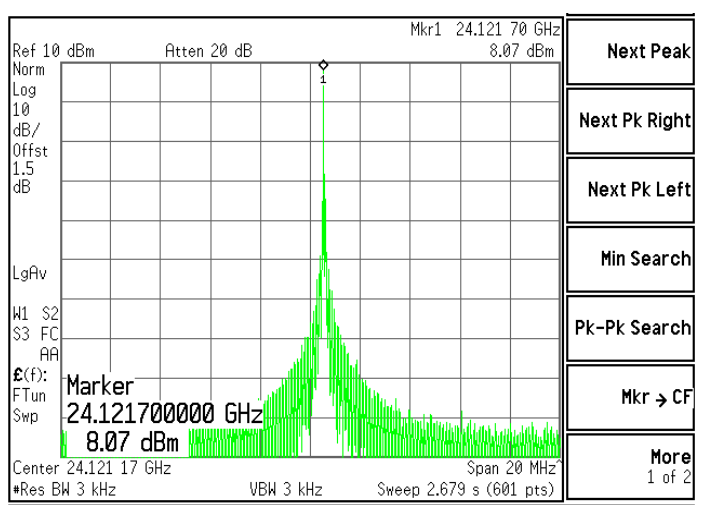

[그림 7] 측정된 송신기 출력 파형

\section{3. 결론}

본 논문에서는 $24 \mathrm{GHz}$ 대역의 $\mathrm{CW}$ 방식의 레이더 송수 신기가 설계되었다. K-대역의 송수신기 회로의 기본 구 조와 전력분배기는 직접 디자인 하였으며 발진기, 주파수 혼합기, 고주파 증폭기는 기존 제품을 사용하였다. IF 증 폭기와 송수신용 마이크로스트립 패치 안테나도 설계하 였다. 제작된 송수신기의 크기는 $35 \times 35 \times 10(\mathrm{~mm})$ 이며 여 러 가지 응용 제품에 사용될 수 있도록 설계되었다. 절전 센서로 사용되기 위한 설계목표를 만족하는 $24 \mathrm{GHz}$ 대역 의 레이더 송수신기가 설계되었다. 향후 RF 부의 삽입손 실을 최소화하기위해 RF 회로를 최적화하고 감지거리를 늘이고 나아가서 탐지된 목표물까지의 거리를 측정할 수 있도록 개선된 송수신기를 개발 할 것이다.

\section{참고문헌}

[1] 양배덕, 밀리미터파 센서의 연구동향, KISTI 기술동향 분석 보고서(89-5884-596-19356) 2005.

[2] I. M. Fernandez, et al., "Low-cost $24 \mathrm{GHz}$ transceiver for unlicensed operation," Electronics Lett. vol. 38, no. 10, pp. 458-459, May 2002.

[3] Roselli, L., et al. "A cost driven $24 \mathrm{GHz}$ Doppler radar sensor development for automotive applications," Microwave Conference, 2005 European, Volume 3, pp. 4-7, Oct. 2005

[4] Alimenti, F., et al., "A low-cost $24 \mathrm{GHz}$ Doppler radar sensor for traffic monitoring implemented in standard discrete-component technology," Microwave Conference, 2007. European, pp. 1441-1444, Oct. 2007.

[5] C. Wang, R. Qian, X. W. Sun, "Low cost K-band radar modules for automobile application," RFIT 2005, pp. 153-155, Dec. 2005.

[6] J. Y. Lee, K. B. Lee, S. H. Choi, "A design of motion detecting sensor using microwave," APMC 2007.

[7] Agilent AMMC-5620(6-20GHz High Gain Amp.) data sheet

[8] Eudyna EMM5206LP(K-Band Oscillator MMIC) data sheet

[9] Hittite HMC292LM3C(GaAs MMIC Double -Balanced SMT Mixer, $17-31 \mathrm{GHz}$ ) data sheet

\section{남 병 창(Byung-Chang Nam)}

[정회원]

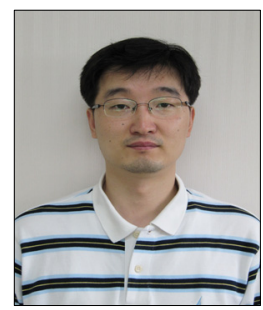

- 1999년 2월 : 고려대학교 물리학 과 (이학석사)

- 2001년 6월 2004년 4월 : (주) 코스페이스 통신연구소 주임연 구원

- 2004년 11월 현재 : (주) 유텔 기술연구소 책임연구원

<관심분야>

위성통신 및 레이더 송수신기 설계

채 규 수(Gyoo-Soo Chae)

[종신회원]

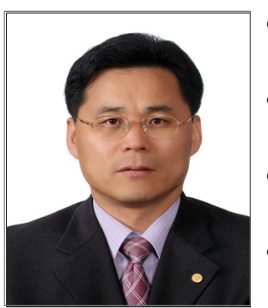

- 1995년 2월 : 경북대학교 전자공 학과 (공학석사)

- 2000년 12월 : Virginia Tech (공학박사)

- 2001년 1월 2003년 2월 : Amphenol Mobile (RF manager)

- 2003년 3월 현재 : 백석대학 교 정보통신학부 교수

<관심분야>

안테나 설계, 초고주파 이론 